\title{
Pyruvate aldolases in chiral carbon-carbon bond formation
}

\author{
Matthew J Walters ${ }^{1,2}$ \& Eric J Toone $\mathrm{e}^{1,2}$ \\ ${ }^{1}$ Department of Chemistry, Duke University, Durham, North Carolina 27708, USA. ${ }^{2}$ Department of Biochemistry, Duke University Medical Center, Durham, \\ North Carolina 27710, USA. Correspondence should be addressed to E.J.T. (eric.toone@duke.edu).
}

Published online 19 July 2007; doi:10.1038/nprot.2007.260

\begin{abstract}
A procedure for the preparation of optically pure $\alpha$-keto- $\gamma$-hydroxy carboxylic acids through stereospecific aldol addition catalyzed by pyruvate aldolases from the Entner-Doudoroff and the DeLey-Doudoroff glycolytic pathways is described. This highly versatile fragment serves as a precursor for a variety of commonly encountered functionalities, including $\beta$-hydroxy aldehydes and carboxylic acids, $\alpha$-amino- $\gamma$-hydroxy carboxylic acids and $\alpha, \gamma$-dihydroxy carboxylic acids. The protocol described here uses recombinant $\mathrm{His}_{6}$-tagged KDPG aldolase for the synthesis of (S)-4-hydroxy-2-keto-4-(2'-pyridyl)butyrate. A protocol for evaluating enantiomeric excess through formation of the $\gamma$-lactone of the dithioacetal followed by chiral-phase gas-liquid chromatography is also described. Enzyme expression and enzymatic synthesis can be accomplished in approximately 1 week. The enzymatic aldol addition proceeds in nearly quantitative yields with enantiomeric excesses greater than $99.7 \%$.
\end{abstract}

\section{INTRODUCTION}

In addition to managing the flow of small molecules that create and support life, enzymes have found great utility in chemical synthesis $^{1-3}$. With the exception of only a few categories, every mechanistic class of reactions known to the organic chemist has an enzymatic equivalent. Enzymes operate with enormous efficiency, providing rate enhancements up to $10^{12}$ over the uncatalyzed reaction, and proceed in aqueous solution, at or near room temperature and neutral $\mathrm{pH}$. Of greatest advantage, enzymes are chiral catalysts, and in many instances carry out reactions stereospecifically. Roughly $60 \%$ of all pharmaceutical agents at market today are chiral, and the well-known problems associated with the use of racemic drugs has led to a growing regulatory pressure for the sale and use of enantiomerically pure formulations $s^{4-8}$. The chiral nature of enzymes facilitates both enantiomerically pure synthesis and the resolution of racemates: today, every major pharmaceutical producer has in place or makes use of a biocatalysis unit.

All synthesis ultimately rests on carbon-carbon bond formation. Although a number of carbon-carbon bond formation strategies are known in nature, the enzymatic aldol reaction has found the greatest use in organic synthesis ${ }^{9,10}$. Originally reported by Whitesides $^{11-14}$ and Effenberger ${ }^{15-17}$, and later elaborated by Wong ${ }^{18-21}$, Fessner $^{22-24}$ and others ${ }^{25-27}$, the dihydroxyacetone phosphate glycolytic aldolases provide access to virtually any 1,3,4-trihydroxy-2-butanone skeleton. Although the enzymes show a strict requirement for dihydroxyacetone phosphate as the nucleophilic component, the enzymes accept virtually any aldehyde as the electrophilic component, providing a powerful set of catalysts. Thus, for example, the use of azide-containing electrophilic substrates facilitated the synthesis of an enormous diversity of azasugar glycosidase inhibitors ${ }^{28}$. Still, difficulties associated with the preparation of dihydroxyacetone phosphate, mixed kinetic and thermodynamic diastereoselectivity and the production of a highly but not differentially functionalized carbon skeleton have limited the broader use of the DHAP aldolases in organic synthesis.

In contrast, aldolases of the Entner-Doudoroff and DeLeyDoudoroff glycolytic pathways catalyze aldol addition of pyruvate to an electrophilic aldehyde to produce a 2-keto-4-hydroxybutyrate skeleton (Fig. 1). This moiety is both highly and differentially functionalized, lending itself to ready synthetic elaboration to, for example, $\alpha$-amino- $\gamma$-hydroxybutyrates, $\alpha, \gamma$-diydroxybutyrates and $\alpha$-hydroxy aldehydes and acids.

2-Keto-3-deoxy-6-phosphogluconate aldolase (KDPG) is a type I pyruvate aldolase of the Entner-Doudoroff glycolytic pathway, which metabolizes glucose through sequential conversion to KDPG followed by retro-aldol cleavage to the key metabolites pyruvate and glyceraldehyde-3-phosphate $(\mathrm{G} 3 \mathrm{P})^{29}$. The equilibrium characterizing KDPG-pyruvate/G3P interconversion lies far toward synthesis ${ }^{30}$, and during aldol addition, KDPG aldolase catalyzes the addition of pyruvate to electrophilic aldehydes with $s i$ facial selectivity (Fig. 1). In contrast to other pyruvate aldolases, KDPG aldolase displays complete kinetic stereoselectivity, further enhancing its utility as a synthetic catalyst ${ }^{31}$. The related enzyme 2keto-3-deoxy-6-phosphogalactonate (KDPGal) aldolase catalyzes the analogous reaction, but with re-facial selectivity, providing access to both stereochemical sequences ${ }^{32}$. The enzyme shows reasonably broad substrate specificity with regard to the electrophilic moiety, accepting straight-chain, branched and cyclic aldehydes, provided they possess polar functionality at C2, C3 or C4. Like the DHAP aldolases, both KDPG and KDPGal aldolase show more restricted substrate specificity with regard to the nucleophilic component, accepting in addition to pyruvate, 2-oxobutyrate and fluoropyruvate.

In the course of developing an enzymatic synthesis of the unnatural amino acid $(2 S, 4 S)$ 2-amino-4-hydroxy-4-(2-pyridyl) butyrate, we developed an enzymatic strategy to prepare the key intermediate (S)-4-hydroxy-2-keto-4-(2'-pyridyl)butyrate ${ }^{33,34}$. The synthesis involves aldol addition between 2-pyridinecarboxaldehyde

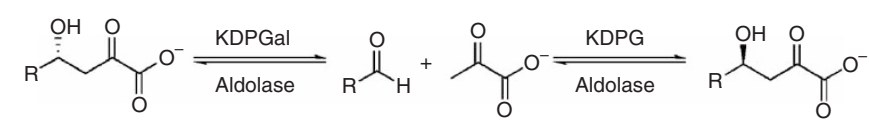

Figure 1 | Pyruvate aldolases in synthesis. 
and pyruvate catalyzed by KDPG aldolase (Fig. 2), and is illustrative of the use of KDPG and KDPGal aldolases for stereocontrolled carbon-carbon bond formation. Formation of the dithioacetal accompanies formation of the corresponding $\gamma$-lactone: this species is sufficiently volatile to permit determination of enantiomeric excess by chiral-phase gas-liquid chromatography.

\section{Experimental design}

This protocol describes the expression and application of KDPG aldolase for stereocontrolled carbon-carbon bond formation. Although we describe the protocol for the specific case of 2pyridinecarboxaldehyde as the electrophilic substrate, the protocol is applicable to other aldehydic substrates. Similarly, substitution of KDPGal aldolase furnishes the analogous series of products epi-

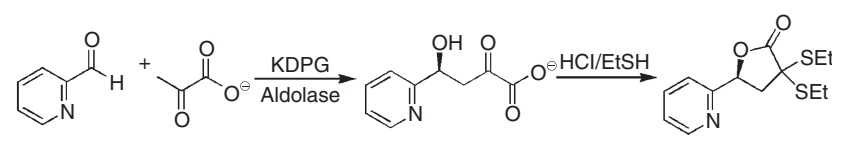

Figure 2 | Synthesis of (S)-4-hydroxy-2-keto-4-(2'-pyridyl)butyrate and lactone formation.

meric at C4. The protocol described here is directly applicable to substrates other than 2-pyridinecarboxaldehyde, although reaction times and enzyme concentrations must be scaled to reflect relative reactivities. The protocols are also applicable for related enzymes-for example, KDPGal aldolase-although substrate specificities must first be evaluated to determine the feasibility of each transformation.

\section{MATERIALS}

REAGENTS

- Kanamycin sulfate (Fluka, cat. no. 60615)

- Terrific broth (EMD Chemicals Inc., cat. no. 1.01629.5007)

- HEPES (Sigma, cat. no. H3375)

- Luria broth (EMD Chemicals Inc., cat. no. 1.10285.5007)

- Agar (Difco, cat. no. 214530)

- Trizma hydrochloride (Sigma, cat. no. T5941)

- Imidazole (Sigma-Aldrich, cat. no. I2399)

-EDTA (Aldrich, cat. no. 431788)

- Nickel(II) sulfate hexahydrate (Sigma-Aldrich, cat. no. 467901)

- His $\bullet$ Bind Resin (Novagen, cat. no. 69670-5)

-pET28b plasmid (Novagen, cat. no. 69865-3)

- KDPG-pet (available from the authors on request ${ }^{36}$ )

- KDPG aldolase (available from the authors on request ${ }^{36}$ )

-BL21 CodonPlus (DE3)-RIL cells (Stratagene, cat. no. 230245)

-SOC media

•IPTG (Calbiochem, cat. no. 420322)

- $12 \%$ (w/v) Tris-HCl gel (Bio-Rad, cat. no. 161-1102)

- Amberlyst 131 (Sigma, cat. no. A2461)

- Sodium chloride (Sigma-Aldrich, cat. no. 204439)

- Sodium hydroxide (Sigma-Aldrich, cat. no. 480878)

- Sodium pyruvate (Sigma-Aldrich, cat. no. P8574)

-2-pyridinecarboxaldehyde (Aldrich, cat. no. P62003)

- Hydrochloric acid (Sigma-Aldrich, cat. no. 435570)

- Oxalacetic acid (Aldrich, cat. no. 171255)

- Magnesium sulfate (Aldrich, cat. no. 203726)

- Methylene chloride (Aldrich, cat. no. 676853)

-Ethanethiol (Aldrich, cat. no. E3708)

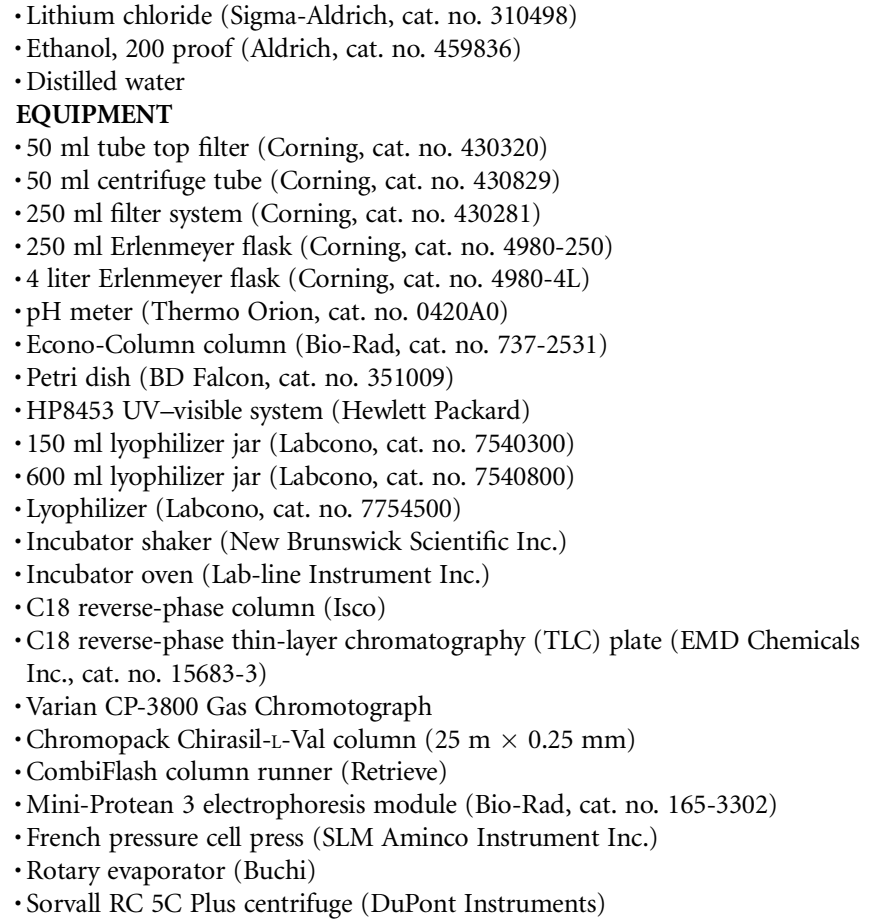

- Lithium chloride (Sigma-Aldrich, cat. no. 310498)

- Distilled water

. $50 \mathrm{ml}$ centrifuge tube (Corning, cat. no. 430829)

$250 \mathrm{ml}$ filter system (Corning, cat. no. 430281)

- $250 \mathrm{ml}$ Erlenmeyer flask (Corning, cat. no. 4980-250)

- pH meter (Thermo Orion, cat. no. 0420A0)

- Petri dish (BD Falcon, cat no. 351009)

- HP8453 UV-visible system (Hewlett Packard)

$150 \mathrm{ml}$ lyophilizer jar (Labcono, cat. no. 7540300)

- Lyophilizer (Labcono, cat. no. 7754500)

- Incubator shaker (New Brunswick Scientific Inc.)

Incubator oven (Lab-line Instrument Inc.)

Coverse-phase column (Isco)

Inc., cat no. 15683-3)

- Varian CP-3800 Gas Chromotograph

-

- French pressure cell press (SLM Aminco Instrument Inc.)

- Sorvall RC 5C Plus centrifuge (DuPont Instruments)

\section{PROCEDURE}

\section{Protein expression of KDPG aldolase}

1| A plasmid containing the gene KDPG-pet ${ }^{36}$, which encodes $\mathrm{His}_{6}$-tagged KDPG aldolase, is chemically transformed into a BL21 CodonPlus (DE3)-RIL cell according to published procedures ${ }^{35}$.

2| Plate $50 \mu \mathrm{l}$ of the transformation mixture on an LB/Kan $\left(50 \mu \mathrm{g} \mathrm{ml}^{-1}\right)$ plate and incubate overnight at $37^{\circ} \mathrm{C}$. PAUSE POINT Plated cells are left in the incubator overnight at $37^{\circ} \mathrm{C}$.

3| Introduce a single isolated colony from the $\mathrm{LB} / \mathrm{Kan}$ plate to $50 \mathrm{ml}$ of TB/Kan $\left(50 \mu \mathrm{g} \mathrm{ml}^{-1}\right)$ and incubate the culture at

$37{ }^{\circ} \mathrm{C}$ for $16 \mathrm{~h}$.

PAUSE POINT To be left in the shaker overnight at $37^{\circ} \mathrm{C}$.

4| Transfer $10 \mathrm{ml}$ of inoculated culture to 1 liter of TB/Kan $\left(50 \mu \mathrm{g} \mathrm{m}^{-1}\right)$ and shake at $37{ }^{\circ} \mathrm{C}$ until an $0 \mathrm{D}_{600}$ of 0.8 is reached.

5| Induce protein expression by adding IPTG $\left(230 \mathrm{mg} \mathrm{liter}^{-1}\right.$, to $\left.1 \mathrm{mM}\right)$ to the cell culture to induce protein expression. IPTG binds to the Lac repressor, inducing protein production. The induced culture is shaken at $37^{\circ} \mathrm{C}$ for an additional $4 \mathrm{~h}$. 
6| Collect the cell culture by centrifugation at $4,000 \mathrm{~g}$ for $10 \mathrm{~min}$ at $4{ }^{\circ} \mathrm{C}$, and freeze the pellet at $-20^{\circ} \mathrm{C}$ overnight.

PAUSE POINT The cell pellet can be stored at $-20^{\circ} \mathrm{C}$ for up to 3 months with minimal loss in enzyme activity.

7| Thaw the pellet on ice and resuspended cells in $30 \mathrm{~mL}$ of $20 \mathrm{mM} \mathrm{HEPES}, \mathrm{pH} 7.5$.

8| Lyse the resuspended cells in a French press at 12,000 psi. Three consecutive passes through the French press ensures complete cell lysis. Alternately, sonication can be used to lyse the cell pellet. Optimal enzyme yields are achieved when lysis is conducted at $4{ }^{\circ} \mathrm{C}$.

9| Remove cellular debris by centrifugation at $14,500 \mathrm{~g}$ for 20 min at $4{ }^{\circ} \mathrm{C}$.

10| Condition the $\mathrm{Ni}^{2+}$ affinity resin by washing with distilled water and charging with nickel(II) sulfate. Then, load the cellular supernatant onto the $\mathrm{Ni}^{2+}$ affinity column and elute $\mathrm{His}_{6}$-tagged enzyme according to published procedures ${ }^{35}$. The protein is eluted with $50 \mathrm{ml}$ of elution buffer and collected in a $50 \mathrm{ml}$ centrifuge tube.

11 Determine the purity of the expressed protein by analysis on $12 \%$ SDS-polyacrylamide gel electrophoresis.

12 Remove imidazole by dialysis of the eluted protein in a 10,000 MWCO cellulose membrane against three changes of $20 \mathrm{mM}$ HEPES, pH 7.5 (2 liters each) at $4^{\circ} \mathrm{C}$ for a total of $24 \mathrm{~h}$.

PAUSE POINT The protein can be stored at $4^{\circ} \mathrm{C}$ for up to 6 months without a significant loss in activity.

13| The protein concentration can be estimated by measuring $A_{280}$ using the extinction coefficient of $16,516 \mathrm{M}^{-1} \mathrm{~cm}^{-1}$. Typical yields for pure KDPG aldolase are about $120-150 \mathrm{mg}$ liter $^{-1}$. The specific activity of the protein is typically

$300-600 \mathrm{U} \mathrm{mg}^{-1}$ (one unit of enzyme catalyzes the conversion of $1 \mathrm{~mol}$ of $\mathrm{KDPG}^{37}$ to pyruvate and glyceraldehyde-3-phosphate per minute at pH 7.0). If desired, the enzyme can be assayed in the retroaldol direction using a coupled lactate dehydrogenase assay ${ }^{29}$. In this assay, the disappearance of pyruvate is monitored by a decrease in absorbance at $340 \mathrm{~nm}$ as NADH is converted into $\mathrm{NAD}^{+}$. Typical kinetic parameters for conversion of KDPG by KDPG aldolase are $K_{\mathrm{m}}$ of $0.1 \mathrm{mM}, k_{\text {cat }}$ of $80 \mathrm{~s}^{-1}$ and $k_{\text {cat }} / K_{\mathrm{m}}$ of $800 \mathrm{mM}^{-1} \mathrm{~s}^{-1}$.

\section{Synthesis of (S)-4-hydroxy-2-keto-4-(2'-pyridyl) butyrate}

14| Dissolve $4 \mathrm{ml}$ (36 mmol) of freshly distilled 2-pyridinecarboxaldehyde in $150 \mathrm{~mL}$ of $20 \mathrm{mM} \mathrm{HEPES}, \mathrm{pH} 7.5$.

! CAUTION 2-pyridinecarboxaldehyde can cause irritation to skin, eye and/or throat.

15| Filter the solution through a $0.22 \mu \mathrm{m}$ filter using a Corning filter system and set this solution aside.

16| Dissolve sodium pyruvate $(3.8 \mathrm{~g}, 34 \mathrm{mmol})$ in $30 \mathrm{ml}$ of $20 \mathrm{mM} \mathrm{HEPES}, \mathrm{pH} 7.5$, in a $50 \mathrm{ml}$ centrifuge tube.

I CAUTION Sodium pyruvate can cause skin irritation.

17| Filter this solution through a $0.22 \mu \mathrm{m}$ filter into a Corning $50 \mathrm{ml}$ tube top filter.

18| Add $5 \mathrm{ml}$ of the sodium pyruvate solution to the 2-pyridinecarboxaldehyde solution and set the rest of the sodium pyruvate solution aside.

19| Add 2-5 mg of KDPG aldolase to the Corning $250 \mathrm{ml}$ reaction vessel and incubate the reaction mixture for $30 \mathrm{~min}$ at room temperature.

20| Add an additional $5 \mathrm{ml}$ of sodium pyruvate solution to the reaction vessel and incubate for an additional $30 \mathrm{~min}$.

21| Repeat Step 20 four more times until the pyruvate solution has been added.

22 Incubate the reaction for a further $24 \mathrm{~h}$. During this incubation, the reaction mixture will develop a faint yellowish color.

- PAUSE POINT The reaction proceeds at room temperature overnight.

23| Transfer the reaction to a $600 \mathrm{ml}$ lyophilizer bottle and freeze the material to liquid nitrogen temperature. Once frozen, lyophilize the reaction mixture.

PAUSE POINT Lyophilization typically proceeds overnight.

24| Transfer the crude material to a 1 liter Erlenmeyer flask and add $250 \mathrm{ml}$ of absolute ethanol to the crude reaction mixture. Stir the mixture at room temperature for $30 \mathrm{~min}$.

25 Filter the insoluble precipitate through a Buchner funnel and into a $500 \mathrm{ml}$ Erlenmeyer flask.

$\triangle$ CRITICAL STEP The insoluble materials are salts; the desired product remains soluble in the ethanol solution. 
PROTOCOL

26| Concentrate the ethanol solution under reduced pressure using a rotary evaporator.

$\triangle$ CRITICAL STEP Heating the solution during concentration results in product decomposition, evidenced by the appearance of a dark brown color.

27| Redissolve the crude solid in distilled water $(60 \mathrm{ml})$ containing LiCl $(1.5 \mathrm{~g}, 0.035 \mathrm{mmol})$.

28| Transfer the solution to a $150 \mathrm{ml}$ lyophilizer jar, freeze the sample to liquid nitrogen temperature and lyophilize overnight.

PAUSE POINT The reaction remains on the lyophilizer overnight or until all the water has been removed.

29| Dissolve the crude material in $50 \mathrm{ml}$ of absolute ethanol with stirring to break up any aggregates. The material is then placed at $-20{ }^{\circ} \mathrm{C}$ for $4 \mathrm{~h}$ to facilitate precipitation.

30| The product as the insoluble lithium salt is then filtered and washed with cold absolute ethanol to recover the desired product.

31 The crude material can be further purified by reverse-phase chromatography. Load crude product on a C18 column (roughly $1 \mathrm{~g}$ crude mixture to $130 \mathrm{~g}$ support) and elute with distilled water at the rate of $70 \mathrm{ml} \mathrm{min}{ }^{-1}$. Collect $10 \mathrm{ml}$ fractions; product is eluted near fractions 15-30. (The C18 column is conditioned with distilled water for 15 min before the sample is loaded onto the column.)

32 Product-containing fractions are identified by spotting on C18 reverse-phase TLC plate and developed in $100 \%$ distilled water. The TLC plate is observed under a UV lamp at 254 or $365 \mathrm{~nm}$ and all UV-active fractions are collected.

33| Pool product-containing fractions and lyophilize to yield product as a white powder.

\section{Synthesis of 2,2-dithioethyl-4-(2'-pyridyl)-4-butyro- $\gamma$-lactone}

34| Dissolve $400 \mathrm{mg}$ of (S)-4-hydroxy-2-keto-4-(2'-pyridyl)butyrate in $6 \mathrm{ml}$ of ethanethiol and $2 \mathrm{ml}$ of concentrated $\mathrm{HCl}$. Stir the mixture for $24 \mathrm{~h}$ at room temperature.

! CAUTION Ethanethiol has a strong stench and is a skin irritant. Concentrated hydrochloric acid will cause skin burns.

PAUSE POINT Reaction can be left stirring overnight.

35| Remove excess ethanethiol by distillation.

36 Extract the resulting solid three times with $10 \mathrm{ml}$ of methylene chloride. Combine the organic extracts, wash with water and dry the organic phase over $\mathrm{MgSO}_{4}$. The organic extracts are then concentrated, leaving a yellow oil.

37| The product is analyzed by chiral gas chromatography using a chiral Chromopack Chirasil-L-Val column $(25 \times 0.25 \mathrm{~m})$ at a temperature of $160{ }^{\circ} \mathrm{C}$ and a pressure of $15 \mathrm{psi}$ to determine the enantioselectivity. A racemic product was synthesized as a calibration standard (Box 1).

? TROUBLESHOOTING

\section{BOX 1 | SYNTHESIS OF RACEMIC 4-HYDROXY-2-KET0-4-(2'-PYRIDYL)BUTYRATE (CHEMICAL)}

Oxalacetic acid $(4.5 \mathrm{~g}, 35 \mathrm{mmol})$ was dissolved in $3 \mathrm{M} \mathrm{NaOH}(20 \mathrm{ml})$ at $0{ }^{\circ} \mathrm{C}$ and brought to $\mathrm{pH}$ 9.0. 2-pyridinecarboxaldehyde (3.75 $\left.\mathrm{g}, 35 \mathrm{mmol}\right)$ was added and the resulting solution was adjusted to $\mathrm{pH}$ 9.0. The reaction was stirred for $1 \mathrm{~h}$ and the pH maintained at 9.0 by periodic addition of $3 \mathrm{M} \mathrm{NaOH}$. When the $\mathrm{pH}$ stabilized at 9.0, the solution was allowed to stir at room temperature for an additional $1 \mathrm{~h}$. The $\mathrm{pH}$ of the reaction was lowered to 3.5 by the addition of strongly acidic (Amberlyst 131) ion exchange $\left(\mathrm{H}^{+}\right)$resin. Spontaneous decarboxylation accompanied acidification. The solution was adjusted to $\mathrm{pH} 7.0$ and lyophilized. The crude material was stirred in $750 \mathrm{ml}$ of ethanol for $30 \mathrm{~min}$ and then filtered. The material was washed with ethanol and precipitated with LiCl as described above. 4-Hydroxy-2-keto-4-(2 \pm -pyridyl)butyrate was converted to racemic 2,2-dithioethyl-4-(2'-pyridyl)-4-butyro- $\gamma$-lactone as described above ${ }^{38}$.

TIMING

Protein expression

Step 1: $2 \mathrm{~h}$

Step 2: $16 \mathrm{~h}$

Step 3: $16 \mathrm{~h}$

Steps 4-6: $8 \mathrm{~h}$

Step 7-9: $1 \mathrm{~h}$ 
Steps 10 and 11: $5 \mathrm{~h}$

Step 12: $24 \mathrm{~h}$

Step 13: $20 \mathrm{~min}$

(S)-4-hydroxy-2-keto-4-(2'-pyridyl)butyrate synthesis

Steps 14-21: $8 \mathrm{~h}$

Step 22: $24 \mathrm{~h}$

Step 23: $24 \mathrm{~h}$

Steps 24-27: $4 \mathrm{~h}$

Step 28: $24 \mathrm{~h}$

Steps 29 and 30: $5 \mathrm{~h}$

Steps 31 and 32: $3 \mathrm{~h}$

Step 33: $24 \mathrm{~h}$

2,2-dithioethyl-4-(2'-pyridyl)-4-butyro- $\gamma$-lactone synthesis

Step 34: $24 \mathrm{~h}$

Steps 35 and $36: 2 \mathrm{~h}$

Step 37: $2 \mathrm{~h}$

\section{? TROUBLESHOOTING}

Troubleshooting advice can be found in Table 1.

TABLE 1 | Troubleshooting table.

\begin{tabular}{lll}
\hline Problem & Possible reason & Solution \\
\hline Low KDPG aldolase yield & $\begin{array}{l}\text { Bad cell line of BL21 CodonPlus (DE3)-RIL } \\
\text { was used }\end{array}$ & Use a fresh cell stock BL21 CondonPlus (DE3)-RIL
\end{tabular}

Insufficiently pure KDPG aldolase

Low (S)-4-hydroxy-2-keto-4-(2'-pyridyl)

butyrate yield

Color formation in product

Cannot find product
Overloaded affinity columns Insufficiently conditioned resins

Insufficient wash before protein elution

Impure 2-pyridinecarboxaldehyde

Inactive KDPG aldolase

Excessive heat applied during product concentration

Isolated the precipitated salts instead of the ethanol fraction
Use at least $10 \mathrm{ml}$ of resin for $80 \mathrm{mg}$ of crude protein Condition resins completely against 10 volumes of $\mathrm{Ni}^{2+}$ buffer

Elute column with 10 bed volumes of wash buffer before beginning elution

Use freshly distilled 2-pyridinecarboxaldehyde

Re-express the KDPG aldolase

Do not heat beyond $30{ }^{\circ} \mathrm{C}$ to avoid formation of elimination product

Product is in the ethanol fraction; isolate this fraction instead of the salt fraction

\section{ANTICIPATED RESULTS}

Typical yields

Typical protein expression yields of KDPG aldolase should be between 180 and $200 \mathrm{mg}$ per liter of growth. Typical isolated yield of (S)-4-hydroxy-2-keto-4-(2'-pyridyl)butyrate is $80-90 \%$ after reverse-phase C18 purification.

\section{Analytical data}

\section{(S)-4-hydroxy-2-keto-4-(2'-pyridyl)butyrate}

${ }^{1} \mathrm{H}$ NMR $\left(400 \mathrm{MHz}, \mathrm{D}_{2} 0\right) \delta 2.93(\mathrm{dd}, 1 \mathrm{H}, J=5.5,15.6 \mathrm{~Hz}), 3.14(\mathrm{dd}, 1 \mathrm{H}, J=8.0,15.0 \mathrm{~Hz}), 5.21(\mathrm{dd}, 1 \mathrm{H}, J=6.0,8.0 \mathrm{~Hz}), 7.41(\mathrm{t}$, $1 \mathrm{H}, J=6.5 \mathrm{~Hz}), 7.56(\mathrm{~d}, 1 \mathrm{H}, J=8.0 \mathrm{~Hz}), 7.93(\mathrm{t}, 1 \mathrm{H}, J=7.7), 8.40(\mathrm{~d}, 1 \mathrm{H}, J=5.5 \mathrm{~Hz}) .{ }^{13} \mathrm{NMR}\left(400 \mathrm{MHz}, \mathrm{D}_{2} 0\right) \delta 41.8,63.5,120.0$, $123.1,138.0,140.9,155.1,167.3,168.0 \mathrm{ppm}$. IR $(\mathrm{KBr}) \vee 1,725,1,715,1,640 \mathrm{~cm}^{-1}$.

\section{2,2-dithioethyl-4-(2'-pyridyl)-4-butyro- $\gamma$-lactone}

${ }^{1} \mathrm{H}$ NMR $\left(300 \mathrm{MHz}, \mathrm{CDCl}_{3}\right) \delta 1.21(\mathrm{q}, 6 \mathrm{H}, \mathrm{J}=7.7 \mathrm{~Hz}), 2.56-2.94(\mathrm{~m}, 6 \mathrm{H}), 5.64(\mathrm{dd}, 1 \mathrm{H}, \mathrm{J}=6.3,9.3 \mathrm{~Hz}), 7.21(\mathrm{dd}, 1 \mathrm{H}, \mathrm{J}=4.1$, $7.0 \mathrm{~Hz}), 7.50(\mathrm{~d}, 1 \mathrm{H}, J=8.0 \mathrm{~Hz}), 7.76(\mathrm{dt}, 1 \mathrm{H}, J=1.9,7.8 \mathrm{~Hz}), 8.59(\mathrm{~d}, 1 \mathrm{H}, \mathrm{J} 4.9 \mathrm{~Hz}) .{ }^{13} \mathrm{C} \mathrm{NMR}\left(300 \mathrm{~Hz}, \mathrm{CDCl}_{3}\right) \delta 13.8,13.9,24.3$, $24.8,46.0,58.3,78.1,120.6,123.5,137.5,148.8,155.9,168.3 \mathrm{ppm}$. 
ACKNOWLEDGMENTS This work was supported by the National Institutes of Health.

COMPETING INTERESTS STATEMENT The authors declare no competing financial interests.

Published online at http://www.natureprotocols.com Reprints and permissions information is available online at http://npg.nature.com/ reprintsandpermissions

1. Gijsen, H.J.M. \& Wong, C.H. Sequential 3-substrate and 4-substrate aldol reactions catalyzed by aldolases. J. Am. Chem. Soc. 117, 7585-7591 (1995).

2. Broadrup, R.L., Sundar, H.M. \& Swindell, C.S. Total synthesis of $12,13-$ desoxyepothilone B (epothilone D). Bioorg. Chem. 33, 116-133 (2005).

3. O'Sullivan, P.T. A concise synthesis of the octalactins. J. Am. Chem. Soc. 126, 2194-2207 (2004).

4. Patel, R.N. Biocatalysis: synthesis of chiral intermediates for drugs. Curr. Opin. Drug Discov. Dev. 9, 741-764 (2006).

5. Patel, R.N. Microbial/enzymatic synthesis of chiral intermediates for pharmaceuticals. Enzyme Microb. Tech. 31, 804-826 (2002).

6. Patel, R.N. Enzymatic preparation of chiral pharmaceutical intermediates by lipases. J. Lipos. Res. 11, 355-393 (2001).

7. Patel, R.N. Biocatalytic synthesis of intermediates for the synthesis of chiral drug substances. Curr. Opin. Biotechnol. 12, 587-604 (2001).

8. Patel, R.N. Enzymatic synthesis of chiral intermediates for drug development. Adv. Synth. Catal. 343, 527-546 (2001).

9. Henderson, D.P. \& Toone, E.J. in Comprehensive Natural Product Chemistry Vol. 3 (ed. Pinto, B.M.) 367-440 (Elsevier Science, Amsterdam, 1999).

10. Modern Aldol Reactions, Vol. 1. Enolates, Organocatalysis, Biocatalysis, and Natural Product Synthesis (Mahrwald, R., Ed.; Wiley-VCH Verg GmbH \& Co. KGaA, Weinheim, Germany, 2004).

11. Lees, W.J. \& Whitesides, G.M. Diastereoselectivity (enantioselectivity) of aldol condensations catalyzed by rabbit muscle aldolase at C-2 of Rchohcho if $\mathrm{R}$ has an appropriately placed negatively charged group. J. Org. Chem. 58, 1887-1894 (1993).

12. Schmid, W. \& Whitesides, G.M. A new approach to cyclitols based on rabbit muscle aldolase (Rama). J. Am. Chem. Soc. 112, 9670-9671 (1990).

13. Borysenko, C.W., Spaltenstein, A., Straub, J.A. \& Whitesides, G.M. Synthesis of aldose sugars from half-protected dialdehydes using rabbit muscle aldolase. J. Am. Chem. Soc. 111, 9275-9276 (1989).

14. Wong, C.H. \& Whitesides, G.M. Synthesis of sugars by aldolase-catalyzed condensation-reactions. J. Org. Chem. 48, 3199-3205 (1983).

15. Straub, A., Effenberger, F. \& Fischer, P. Enzyme-catalyzed reactions. 4. Aldolase-catalyzed $\mathrm{C}-\mathrm{C}$ bond formation for stereoselective synthesis of nitrogen-containing carbohydrates. J. Org. Chem. 55, 3926-3932 (1990).

16. Ziegler, T., Straub, A. \& Effenberger, F. Enzyme-catalyzed reactions. 3. Enzymecatalyzed synthesis of 1-deoxymannojirimycin, 1-deoxynojirimycin, and 1,4dideoxy-1,4-imino-D-arabinitol. Angew. Chem. Int. Ed. 27, 716-717 (1988).

17. Effenberger, F. \& Straub, A. A novel convenient preparation of dihydroxyacetone phosphate and its use in enzymatic aldol reactions. Tetrahedron Lett. 28 1641-1644 (1987).

18. Alajarin, R., Garciajunceda, E. \& Wong, C.H. A short enzymatic-synthesis of L-glucose from dihydroxyacetone phosphate and L-glyceraldehyde. J. Org. Chem. 60, 4294-4295 (1995).
19. Liu, K.K.C. Use of dihydroxyacetone phosphate dependent aldolases in the synthesis of deoxyazasugars. J. Org. Chem. 56, 6280-6289 (1991).

20. Pederson, R.L. \& Wong, C.H. Enzymatic aldol condensation as a route to heterocycles-synthesis of 1,4-dideoxy-1,4-imino-D-arabinitol, fagomine, 1-deoxynojirimycin and 1-deoxymannojirimycin. Heterocycles 28, 477-480 (1989).

21. Pederson, R.L., Kim, M.J. \& Wong, C.H. A combined chemical and enzymatic procedure for the synthesis of 1-deoxynojirimycin and 1-deoxymannojirimycin. Tetrahedron Lett. 29, 4645-4648 (1988).

22. Zannetti, M.T., Walter, C., Knorst, M. \& Fessner, W.D. Fructose 1,6-bisphosphate aldolase from Staphylococcus carnosus: overexpression, structure prediction, stereoselectivity, and application in the synthesis of bicyclic sugars. Chem. Eur. J. 5, 1882-1890 (1999).

23. Eyrisch, 0. \& Fessner, W.D. Disaccharide mimetics by enzymatic tandem aldol additions. Angew. Chem. Int. Ed. 34, 1639-1641 (1995).

24. Fessner, W.D. \& Walter, C. Enzymatic C-C Bond Formation in Asymmetric Synthesis 97-194, 33rd edn., Vol. 184 (Springer-Verlag, Berlin, 1997).

25. Takayama, S., McGarvey, G.J. \& Wong, C.H. Microbial aldolases and transketolases: new biocatalytic approaches to simple and complex sugars. Annu. Rev. Microbiol. 51, 285-310 (1997).

26. Wymer, N. \& Toone, E.J. Enzyme-catalyzed synthesis of carbohydrates. Curr. Opin. Chem. Biol. 4, 110-119 (2000).

27. Fessner, W.D. \& Helaine, V. Biocatalytic synthesis of hydroxylated natural products using aldolases and related enzymes. Curr. Opin. Biotechnol. 12, 574-586 (2001)

28. Kajimoto, T. Enzyme-catalyzed aldol condensation for asymmetric-synthesis of azasugars-synthesis, evaluation, and modeling of glycosidase inhibitors. J. Am. Chem. Soc. 113, 6187-6196 (1991).

29. Griffiths, J.S. Cloning, isolation and characterization of the Thermotoga maritima KDPG aldolase. Bioorg. Med. Chem. 10, 545-550 (2002).

30. Meloche, H.P. \& O'Connell, E.L. 2-Keto-3-deoxy-galactonate-6-phosphate aldolase from Pseudomonas-saccharophila. Methods Enzymol. 90, 263-269 (1982)

31. Allen, S.T., Heintzelman, G.R. \& Toone, E.J. Pyruvate aldolases as reagents for stereospecific aldol condensation. J. Org. Chem. 57, 426-427 (1992).

32. Cotterill, I.C., Henderson, D.P., Shelton, M.C. \& Toone, E.J. The synthetic utility of KDPGal aldolase. J. Mol. Catal. B-Enzym. 5, 103-111 (1998).

33. Henderson, D.P., Shelton, M.C., Cotterill, I.C. \& Toone, E.J. Stereospecific preparation of the $\mathrm{N}$-terminal amino acid moiety of nikkomycins $\mathrm{K}-\mathrm{X}$ and $\mathrm{K}-\mathrm{Z}$ via a multiple enzyme synthesis. J. Org. Chem. 62, 7910-7911 (1997).

34. Henderson, D.P. et al. The synthetic utility of pyruvate aldolases: preparation of nikkomycin amino acids. Abst. Pap. Am. Chem. Soc. 216, U226-U226 (1998).

35. Sambrook, J. \& Russell, D.W. Molecular Cloning: A Laboratory Manual, 3rd edn. (Cold Spring Laboratory Press, Cold Spring Harbor, NY, 2001).

36. Fullerton, S.W.B. et al. Mechanism of the class I KDPG aldolase. Bioorgan. Med. Chem. 14, 3002-3010 (2006).

37. O'Connell, E.L. \& Meloche, H.P. Enzymic-synthesis of 2-keto-3-deoxygluconate 6-phosphate using 6-phosphogluconate dehydratase. Methods Enzymol. 89, 98-101 (1982).

38. Cornforth, J.W., Firth, M.E. \& Gottshack, A. The synthesis of $N$-acetylneuraminic acid. Biochem. J. 68, 57-61 (1958). 